\section{P317 IMPLEMENTATION OF CONTINUOUS QUALITY INITIATIVE FOR IMPROVING KEY INDICATORS IN HIV TREATMENT CASCADE IN WESTERN NIGERIA}

Saheed Usman*, Chiedozi Akueshi, Adetosoye Adebanjo, Femi Owolagba, Jay Osi-Samuels, Babatunde Ladi-Akinyemi, Babatunde Akinbinu, Patrick Akande, Oluremi Olaitan, Matthias Alagi, Eke Ofuche, Oluwatoyin Jolayemi, Prosper Okonkwo. APIN Public Health Intiatives, Abuja, Nigeria

\subsection{6/sextrans-2019-sti.428}

Background Continuous Quality Improvement (CQI) is a quality management process that encourages all health care team members to continuously ask critical questions especially using CQI initiative that employs a Plan-Do-Study-Act (PDSA) cycle to test a proposed change or initiative. Granular Site Management (GSM) was established to enhance identification of innovations or best practices and scale across facilities and ensuring resources application efficiency. The aim of the study was thus to improve key indicators in HIV program treatment cascade in Western Nigeria.

Methods The CQI implementation was in four selected (secondary \& tertiary) facilities where a cumulative 6000 patients living with HIV (PLHIV) in care. The major drivers of poor performance on key program indicators were identified with underlying causes, in-depth analysis \& review of performance done then using CQI approach to implement change strategies for improvement, monitor and periodically evaluate change ideas for improved outcomes.

Results A total of four facilities were included in this study. Escort service was implemented for all newly identified HIV positive patients which made linkage to care improve from $50 \%$ to $95 \%$ within a space of six months. Task shifting \& sharing, improved health education for clients, introduction of biometrics capturing for all clients and creation of additional hub for sample logging to viral load reference laboratory all helped to improve viral load uptake \& suppression from < $30 \% \&<80 \%$ to $79 \% \&>80 \%$ respectively. Other CQI initiatives also greatly improved the positivity rate, total number of positives placed on treatment and retention in care.

Conclusion This CQI initiative using GSM approach has been used to achieve peer learning and cross fertilization of change ideas among facilities thus encouraging them to innovate and have a problem solving approach to achieve programmatic best practices thus ensuring program \& resources application efficiency.

Disclosure No significant relationships.

\section{P318 THE IMPLICATIONS OF EFFECTIVE SCHOOL-BASED PREVENTION FOR RISK OF STD ACQUISITION}

${ }^{1}$ Kathleen Ethier*, 'Leah Robin, ${ }^{2}$ Lisa Barrios. 'Centers for Disease Control and Prevention, Division of Adolescent and School Health, Atlanta, USA; ${ }^{2}$ Centers for Disease Control and Prevention, Adolescent and School Health, Atlanta, USA

\subsection{6/sextrans-2019-sti.429}

Background Effective school-based HIV and STD prevention improves health education, access to health services, parent engagement, and increases school connectedness (SC). SC the degree to which students believe that adults and peers in the school care about them and their success - has long termimplications for sexual behavior, experience of sexual violence, and STD acquisition into adulthood. The current analyses examine the associations of activities to increase school connectedness and health-related experiences and behaviors among high school students in 347 schools from 17 school districts funded by CDC's Division of Adolescent and School Health (DASH) from 2013 to 2018 to implement HIV and STD prevention.

Methods We used data from DASH's Program Evaluation Reporting System (PERS) and School Health Profiles survey (Profiles) to assess implementation of four school connectedness activities and data from the Youth Risk Behavior Survey (YRBS) to assess youth behaviors and experiences. We examine whether level of implementation of SC in Year 3 of the program was related to STD risk at the end of Year 4.

Results SC, as measured by PERS, was significantly related to decreased forced sex $(O R=0.99, C I=0.99-1.0, p<0.001)$, sexual initiation $(\mathrm{OR}=0.99, \mathrm{CI}=0.98-0.99, \mathrm{p}<0.001)$, current sexual activity $(\mathrm{OR}=0.99, \quad \mathrm{CI}=0.98-0.99, \quad \mathrm{p}<0.001)$, and increased dual protection $(\mathrm{OR}=1.02, \mathrm{CI}=1.00-1.04, \mathrm{p}<0.05)$. SC as assessed by Profiles was related to lower levels of sexual dating violence $(\mathrm{OR}=0.98, \mathrm{CI}=0.97-0.99, \mathrm{p}<0.001)$, initiation $(\mathrm{OR}=0.98, \mathrm{CI}=0.98-0.99, \mathrm{p}<0.001)$, current sexual activity $(\mathrm{OR}=0.99, \mathrm{CI}=0.98-0.99, \mathrm{p}<0.001)$, and increased condom use $(\mathrm{OR}=1.01, \mathrm{CI}=1.00-1.02, \mathrm{p}<0.01)$.

Conclusion The DASH approach to primary prevention of HIV and STD is effective in improving sexual risk behaviors at a population level in schools. The current analyses demonstrate that increased implementation of school-connectedness specific activities are associated with reduced behaviors and experiences tied to STD acquisition, with significant implications for those experiences into adulthood.

Disclosure No significant relationships.

\section{P319 RANDOMIZED CONTROLLED TRIAL OF 1\% AND 5\% 5- FLUOROURACIL COMPARED TO $90 \%$ TRICHLOROACETIC ACID FOR ANOGENITAL WART TREATMENT}

${ }^{1}$ Ika Anggraini* ${ }^{2}$ Aida Hoemardani, ${ }^{3}$ Hanny Nilasari, ${ }^{1}$ Wresti Indriatmi. ${ }^{1}$ Department of Dermatology and Venereology Faculty of Medicine Universitas Indonesia - Dr. Cipto Mangunkusumo National General Hospital, Jakarta, Indonesia; ${ }^{2}$ Department of Dermatology and Venereology Dharmais Cancer National Hospital, Jakarta, Indonesia; ${ }^{3}$ Department Dermatology and Venereology Faculty of Medicine Universities Indonesia - Dr. Cipto Mangunkusumo National General Hospital, Jakarta, Indonesia

\subsection{6/sextrans-2019-sti.430}

Background Anogenital wart is one of the most common sexual transmitted infection with varying number of cure rate. Currently self applied therapy is not widely available in Indonesia, except 5-Fluorouracil (5-FU) which could be obtained from 5-FU solution and had been tested for the drug stability. Standard topical therapy in Indonesia is 90\% trichloroacetic acid solution (TCA), need 4-6 times until lesion improved. Since TCA requires weekly visit, so it could decrease the treatment compliance. Therefore the self applied therapy may become more favourable. We aim to know the effectivity and safety of $1 \% 5$-FU and 5\% 5-FU cream compared to $90 \%$ TCA solution in the treatment of anogenital wart.

Methods A randomised control study with intention to treat analysis conducted on January-Mei 2018 in 72 subjects. Allocated to three group 1\% 5-FU, 90\% TCA, and 5\% 5-FU. Response of therapy and side effect (subjective and objective) were evaluated each week, up to seven weeks.

Results Evaluation at week 7 demonstrated that there was no significant difference on the effectivity between $1 \% 5$-FU and $90 \%$ TCA $(p=0,763)$, as well as on the effectivity between 